\title{
DESAFÍOS ACTUALES DE LA PEDAGÓGICA DE LA LIBERACIÓN: UNA MIRADA DESDE LA FILOSOFÍA DE LA EDUCACIÓN EN AMÉRICA LATINA
}

Holger Díaz Salazar

\section{Introducción}

Siendo estudiante de Psicopedagogía en la universidad, siempre me impresionó críticamente la forma en que me ofrecían los profesores la 'cátedra', en torno a las disciplinas del currículo universitario. Observaba también que las relaciones entre profesores y alumnos eran bastante jerárquicas y con un diálogo escaso. También caí en cuenta que los enfoques disciplinares y la tradición

- Magister en Estudios Internacionales, especialización Relaciones Internacionales; especialista en Planejamento e Gestão de Educação a distãncia y Educación a Distancia, Director del Posgrado de Educación de la UPS-Ecuador. Docente de la Universidad Politécnica Salesiana. 
pedagógica eran un tanto extraños para mí y para mis compañeros de aula. Muchos contenidos disciplinares, por ejemplo, del área filosófica estaban anclados en la tradición greco-romana, latino-germánica y la cristiandad (presocráticos, socráticos, etcétera) y casi no se hablaba de aquellos saberes propios de nuestra tierra. Me parecía que había un desgano por lo nuestro. Más tarde comprendí que había una pedagógica —no es igual a pedagogíaque venía de Europa, se había transmitido por tradición a lo largo del sistema educativo ecuatoriano y, por cierto, eso era lo que se debía aprender y reproducir inconscientemente porque parecía lo más natural. Esa tal 'naturalidad' - porque todo lo que está más allá de la naturaleza física no es natural - hizo que sospechara y me preguntara por una pedagógica distinta, que no procediera de la metrópoli sino desde lo que somos y estamos siendo los latinoamericanos. Hoy soy consciente de que hay otra posibilidad (poder ser) de comprender los saberes, la ciencia y la humanística, en términos de próximo a próximo y entre próximos, $y$, a la vez, de considerar que se trata de un gran desafío para ecuatorianos y latinoamericanos. Entre estas y otras posibilidades de mi propio pensar nace la temática de Los desafíos actuales de la pedagógica de la liberación en América Latina.

Desde una casuística educativa planteo también la experiencia actual que tengo en mis clases de realidad nacional en la universidad. En una de éstas, en el año 2006, época de elecciones nacionales, presenté a los estudiantes de Comunicación Social el documental BONITA: bananos feos; no era producto de la televisión ecuatoriana ni de índole sensacionalista, más bien mostraba la lacerante realidad social padecida por muchos ecuatorianos, captada por cámaras y vivida real y existencialmente por una artista escosesa, Jan Nimmo, en la hacienda Los Álamos de la provincia del Guayas. La propiedad bananera 
era y sigue siendo de Álvaro Noboa Pontón, el mayor magnate de la fruta en el país.

Cuenta Jan Ninmo que detrás de las haciendas y el sistema bananero existe una amarga historia de colonialismo, explotación y violencia contra los trabajadores. Escandaliza e indigna porque es un fenómeno cotidiano en nuestros países, entre quienes tienen poder económico y generalmente político — han llegado al gobierno —, y los que no tienen ningún poder económico ni político, ni oportunidades justas de gobernar sus naciones.

El documental muestra una injusta e ignominiosa realidad social e histórica entre el plutócrata y las oprimidas víctimas; evidencia recurrente en otros sucesos similares de las sociedades latinoamericanas durante varios siglos de colonialismo y explotación inmisericorde.

Los poderosos y los sacrificados de este mundo representan dos visiones del mundo y de la vida distintas entre sí, y no obstante en juego; se trata de la eterna contradicción entre la oligocracia y la plebe. A priori nos referiremos a los términos poderoso — que denominaremos ego dominador - y víctima - que denominaremos alter dominado - como parte inherente a una dialéctica positiva y negativa, en las relaciones de contradicción ontológica e histórica. Cuando nos remitimos a América Latina el nexo dialéctico se expresa en la lid de relaciones de colonialidad de poder etnocéntrico con los distintos pueblos de la región, relaciones de poder asimétrico que deberán ser negadas y superadas mediante nuevos paradigmas conceptuales teóricos y metodológicos, a partir de nuestras auténticas realidades, desde lo que somos y estamos siendo. Las ciencias sociales y filosóficas son la piedra angular a la hora de negar el colonialismo eurocéntrico y norteamericano; en otras palabras, se trata de dar un giro descolonizador a las relaciones del saber racista y superar las categorías dicotómicas de superior e inferior. 
La dialéctica positiva, propia del ego dominador, ha asumido para sí una pedagógica de la dominación, entendida como la relación jerárquica, falocrática, machista y sádica del padre ${ }^{1}$ hacia el hijo que termina en el filicidio generacional por las gerontocracias del poder etnocéntrico. En la pedagógica de la dominación, la falocracia erótica (el Estado) por medio del filicidio pedagógico (la cultura) termina en el fratricidio político (el ser humano). En cambio, en la dialéctica negativa el alter dominado debe asumir para sí y éticamente una pedagógica de la liberación, entendida como la relación cara a cara, padre-hijo, y en su extensión, maestro-discípulo, político-ciudadano, etcétera, para la superación ontológica de una larga historia pedagógica europea y norteamericana. La pedagógica de la liberación es, entonces, una antipedagógica del sistema, la superación fálica del Estado como padre y del hijo, la cultura, como maldición. En otras palabras, la pedagógica de la liberación es la metafísica del cara a cara, como siempre anterior al Otro; el hijo heredero de la tradición y, a la vez, exterioridad de la misma, que evoluciona y re-voluciona; que transita de exterioridad en exterioridad y de totalidad a alteridad, y no meramente ex-volutiva y dialéctica, sino sobre todo analéctica y dis-volutiva.

La pedagógica de la liberación implica una opción trascendental (metafísica) del cara a cara o mejor dicho del padre-hijo, maestro-discípulo, médico-enfermo, entre otras modalidades de relación amorosa intersubjetivas. Siendo así, la pedagógica de la liberación se plantea para los pueblos de América Latina como un desafío ontológico, histórico y metafísico fundado en un proceso permanente de: 1 . Ruptura crítica de las relaciones de colonialidad del poder etnocéntrico; 2. Reconocimiento ontológico, histórico y metafísico de lo que 
somos y estamos siendo; y 3. Praxis continua del método dialógico como estrategia de liberación.

Lo anteriormente enunciado permite preguntarse: ¿Cuáles son los desafíos que nos plantea la pedagógica de la liberación latinoamericana en la actualidad? Específicamente queremos indagar: ¿Cuáles son los elementos paradigmáticos de ruptura crítica de las relaciones de colonialidad del poder etnocéntrico?, ¿qué significatividad filosófica conlleva el reconocimiento ontológico, histórico y metafísico de lo que somos y estamos siendo? Y, finalmente, ¿por qué el método dialógico es una estrategia de liberación humana en las condiciones geopolíticas, históricas, antropológicas y educativas de América Latina?

De forma general, el estudio permite contribuir al fortalecimiento de la conciencia crítica-histórica de los sujetos sociales y educativos comprometidos con la praxis de la filosofía de la educación latinoamericana. De manera específica el estudio trata de:

1. Identificar los componentes paradigmáticos de ruptura crítica de las relaciones de colonialidad del poder etnocéntrico.

2. Comprehender el significado filosófico del reconocimiento ontológico, histórico y metafísico de lo que somos y estamos siendo.

3. Explicar el método dialógico como una estrategia de liberación humana en las condiciones geopolíticas, históricas, antropológicas y educativas de América Latina.

La importancia del tema radica en que se debe (deber-ser) superar hoy más que nunca las relaciones de colonialidad eurocéntricas y norteamericanas impuestas en América Latina, dadas por un lado a través del 'saber 
científico' y, de otro lado, mediante relaciones falocráticas (Estado) que culminan en el filicidio (muerte del hijo, la cultura) generacional por las aristocracias en el poder. En este sentido, es un compromiso histórico el que se promueva, tanto desde la filosofía de la educación latinoamericana como desde los sujetos implicados en los sistemas educativos, una pedagógica que se ancle en la concepción de la pedagogía problematizadora y de la pregunta.

Este estudio aborda, por un lado, la ruptura crítica de las relaciones de colonialidad del poder etnocéntrico; por otro lado, el reconocimiento ontológico, histórico y metafísico de lo que somos y estamos siendo en América Latina, y finalmente, la praxis del método dialógico como estrategia de liberación.

\section{Ruptura crítica de las relaciones de colonialidad del poder etnocéntrico; dos visiones del mundo y de la vida}

Como nunca antes en la historia de la humanidad, se tiene mucho más conciencia de la relación dialéctica entre el poderoso y la víctima. El poderoso se define por la riqueza, poder y prestigio. No así la víctima que está condicionada por la pobreza, el no-poder y el no-prestigio; conceptos que se expresan a través de la desvalidez, miseria, explotación, esclavitud, servidumbre, minusvalía e inhumanidad. Son situaciones reales y condicionantes del ser humano y social.

Los unos, con ventaja, se encuentran con los otros, con desventaja, pero están presentes en una u otra situación y condición. La situación es estar en un contexto y, por tanto, estar siendo. De tal modo la situación no es sólo apariencia física o fenomenológica sino también ontológica y metafísica. 
La condición es circunstancial o accidental a sí misma, pero no menos irrelevante que la situacionalidad del ser humano. La condición es innatural, artificial y, por ende, modificable.

Tanto el poderoso como la víctima se hallan ubicados e interpretados en una situación y en una condición. Con Zubiri ${ }^{2}$ podríamos afirmar que nos hallamos en un 'campo de realidad' consistente en la apertura respectiva de cada cosa real a otras, o de cada objeto del campo a los otros; ambos campos de realidad se entrelazan unos con otros y, en consecuencia, determinan una posición que nos ofrecen una primera versión de la realidad.

A priori podríamos representar el poderoso como 'ego' y la víctima como 'alter'.

El ego es la encarnación de la mismidad y el alter la encarnación de la otredad. Compréndase la mismidad como la idea que apela a la unicidad del ser, a la dimensión estructural del ser, es decir, a lo que se mantiene a pesar del tiempo; la mismidad es aquello que no se detiene en el proceso que va. En términos platónicos, la mismidad es el eterno retorno de lo mismo, es la circularidad del tiempo y del espacio; interpretando hoy a Moreano (2002: 259) diríamos que es el catoblepas ${ }^{3}$, esto es, la 'interminable tautogolía de Lo Mismo'. De hecho, es la pedagógica de la dominación. Contrariamente a dicha ontología, la no repetición de lo Mismo es la Otredad, es decir, el Otro como otro (Levinas, 1977: 60): "el enemigo, el Otro' (Moreano, 2002: 258) que 'ya no estaba' [está] dentro sino fuera, en otra cultura, en otra historia, en otro hemisferio" (ibíd.).

\section{La colonialidad del poder etnocéntrico}

Enunciar la ruptura es poner de manifiesto la superación de las relaciones de colonialidad y moderni- 
dad etnocéntricos iniciadas con el mal denominado 'Descubrimiento de América' o por lo que Dussel ${ }^{4}$ llama "nacimiento de la modernidad" europea. Se trata de la confrontación de Europa con el Otro desconocido, llámese indias orientales, África o América. De todas formas, el Otro no fue descubierto como Otro sino encubierto como lo Mismo. De allí que el año 1492 será el nacimiento de la modernidad y por tanto el origen del mito "de la violencia sacrifical y el proceso de 'en-cubrimiento' de lo no europeo" (ibíd.). Se impone el Mismo como lo mismo en las Américas a través de un proceso racial, primero biológico y hoy cultural, sostendrán Hard y Negri (2002: 173176).

Será la categoría de raza a lo largo de la modernidad y la posmodernidad europea una categoría mental que definirá las relaciones de colonialidad etnocéntricas, porque la raza se establece como instrumento de estratificación social fundamental de la población; según Quijano (Quijano, 2000a: 20) "es el modo básico de clasificación social universal de la población mundial". La colonialidad entonces se funda sobre la concepción racial que es, a su vez, uno de los elementos centrales justificativos del capitalismo moderno.

Con la configuración de América, en el mismo instante y en el mismo movimiento histórico, el capitalismo se vuelve mundial y establece relaciones hegemónicas de colonialidad y modernidad; ambas asociadas instalan un patrón de poder dominante. En esas relaciones se fueron creando nuevas formas de designar al Otro, bajo la denominación de: "indios, negros, aceitunados, amarillos, blancos, mestizos, y las geoculturales del colonialismo, como América, África, Lejano Oriente, Cercano Oriente (las dos últimas llamadas, más tarde, Asia), Occidente o Europa (Europa Occidental después)" 5 . La modernidad natulariza el racismo como si fuera biológico y por siem- 
pre; es decir, ontologiza el racismo como un estado de naturaleza a través del cual se establecen naturalmente razas superiores e inferiores; aquellas como civilizadas y éstas como incivilizadas o salvajes, transmitido por el discurso académico y educativo como primitivos-bárbaros vs. civilizados. Mito y falacia a la vez. Concepciones que se levantan a priori sobre las categorías de "Evolucionismo y dualismo" (Quijano, 2000: 220).

Del mito de la raza superior como fundamento de la civilidad europea nace la perspectiva evolucionista típicamente unilineal y unidireccional de la historia humana. A la versión evolucionista se adjunta el mito dualístico de la separación del cuerpo y del alma, muy bien utilizado por la teología europea para la conquista de América; tanto en Europa como en América se trata de una larga historia "de la primacía del alma sobre el cuerpo"; en verdad, el alma es el objeto por excelencia de la salvación teológica y el cuerpo el "resurrecto, como culminación de la salvación” (ibíd.: 223-224), en la sociedad de hoy profundamente monetarizada.

En fin, la modernidad funda la imagen irreal de un ser con respecto a un no-ser (ser y no-ser). El ser es alguien y el no-ser, don nadie (el Otro), por ende es una relación etnocéntrica basada en el idea de las razas inferiores. De hecho éstas están condenadas a la barbarie, la dominación y la explotación 'por no ser sujetos racionales' (ibíd.: 225).

Desde hace mucho tiempo sentimos vocación por el pensamiento latinoamericano que viene instituyendo una postura crítica ante los conocimientos y saberes etnocéntricos; la crítica va relacionada a la índole colonial y eurocéntrica 'de los saberes sociales' en la región, al sistema de segregación que están detrás o sirven de base, y al mismo mito de la modernidad como paradigma civilizatorio mundial. 
Según Montero (Lander, s/a: 27-28, doc. en pdf) en América Latina estamos en la posibilidad de ver de otro modo el mundo, de interpretarlo y actuar sobre el mismo. Este sistema tripartito es en realidad una episteme, otra modalidad de conocimiento que nos permite ejercer la "capacidad de ver y hacer desde una perspectiva Otra, colocada al fin en el lugar de Nosotros". La episteme se define por las ideas de relación, liberación, redefinición de la misión del investigador social, del 'carácter histórico' y 'relativo del conocimiento' y la 'pluralidad epistémica', del enfoque de dependencia y resistencia y del sometimiento de los métodos a revisión.

\section{Reconocimiento ontológico, histórico y metafí- sico de lo que somos y estamos siendo}

La pedagógica de liberación latinoamericana conlleva la negación de la negación de las relaciones de colonialidad de poder etnocéntrico en la fase de reconocimiento de la Otredad como categoría metafísica e histórica, es decir, en la concepción de 'el Otro' como otro distinto y no como diferente.

\section{La Otredad}

Es calidad de 'el Otro', la alteridad por excelencia. En el discurso filosófico de Levinas (1977: 57-63), el Otro es metafísicamente deseado y tiende hacia lo totalmente otro, al Otro absoluto; el deseo es de lo absolutamente Otro y lo absolutamente Otro, es el Otro como tal. De tal modo, la metafísica del Otro precede a la ontología; ésta es totalidad y aquella trascendencia. La totalidad pertenece a lo Mismo como lo mismo y la trascendencia al Otro como otro que es la exterioridad por sí misma. 
En el pensamiento filosófico de Dussel (1973b: 119), el Otro es momento metafísico que está más allá de lo ontológico, esto es, "como lo más allá, siempre exterior de lo Mismo". En la dialéctica monológica de occidente, el Otro es diferente de lo Mismo, mientras que en la analéctica ${ }^{6}$ dialógica lo otro como Otro es metafísicamente distinto.

El Otro como diferencia es inherente a la mismidad moderna. En Descartes, lo Otro queda encerrado en la mismidad del yo pienso (ego cogito), el cuerpo y el alma son dos realidades diferentes y separadas una de otra; incluso Platón inaugura la dicotomía cuerpo y alma, introyectada por siglos más allá del Atlántico, no superada por la modernidad, peor aún por la posmodernidad; la mismidad cartesiana es un solipsismo a ultranza que trata de encontrar el Otro pero sin éxito. Hay una involución diáléctica.

En Kant, el Otro no está presente en el horizonte del saber y conocer; el Otro es un postulado de fe y orden moral; exclusivamente queda restringido a una mera fe racional. Si se trata del ser humano, éste queda reducido a un simple ente físico-biológico y nada más.

Fichte con su Yo trascendental integra en su pensar la dialéctica de lo mismo y lo otro: "Lo Mismo originario es el Yo absoluto" en que "todo debe ser dado al Yo por el Yo mismo" (ibíd.: 110). Sólo en la conciencia única se da la diferencia; el no-yo (lo otro) se opone al yo (ser). El yo como opuesto al no-yo es producto del Yo absoluto $y$ en consecuencia es base de la diferencia.

Quien introyecta mucho más perfectamente la idea de 'lo otro' en la mismidad del Yo es Schelling. En el autor, el sujeto y el objeto del pensar como autoconciencia son uno; la autoconciencia es un acto y el Yo procede del acto de autoconciencia, fuera de ésta no existe nada, el 
Yo es nada; en cambio, 'Lo otro' es el fruto de una diferencia interna a 'Lo Mismo' (ibíd.).

Llegamos a Hegel, al autor de la dialéctica de 'lo mismo' y 'lo otro' en términos de 'Señor-esclavo' que tendrá un gran impacto posterior en el análisis marxista. En Hegel podemos identificar dos momentos de su sistema de pensamiento: por un lado, la conciencia como el aparecimiento del espíritu, y la autoconciencia como región ignorada y duplicada en otra autoconciencia. Siendo así: “"El Otro' no es sino la mediación que hace que la autoconciencia se reconozca y se supere desde sí para sî" (ibíd.: 114).

Posteriormente, ni el mismo Marx podrá superar la dialéctica hegeliana a pesar de haber formulado la extinción del Estado burgués a través de la dictadura del proletariado para pasar a la sociedad sin clases. Es que la concepción de 'lo otro' como 'el Otro' se expresa metafísicamente como distinto y no como diferente. Marx, a pesar de su discurso progresista, queda atrapado en el viejo paradigma de lo Mismo. El Otro como otro distinto queda sometido a lo Mismo europeo ${ }^{7}$.

Lo otro como Otro es metafísicamente distinto porque no es totalidad sino intotalidad y está más allá de lo ontológico. Se trata del 'cara a cara' en el sentido de lo inmediato, lo próximo y lo que está frente a frente. En esta relación no hay mediación sino apertura y experiencia primera: "es el más allá de la totalidad mundana, previa a ella misma y originaria" (Dussel, 1973b: 120). Es la apertura de persona a persona y no de objeto a objeto, por tanto, es una relación irrespectiva de justicia, amor, amistad, benevolencia y diálogo. Más allá de la comprensión del rostro del otro se vislumbra la exterioridad del Otro como alter con su libertad y expresividad inviolable. Tomando los términos de la teoría política diríamos que es la soberanía de la persona como otro distinto al otro. 
En la tradición hebreo-judía el Otro como otro es Yo soy el que soy y mi próximo, el prójimo, conmigo y otros.

El cara a cara es una verdad primera y un misterio incomprensible a mi mundo. Es la relación entre un yo y un tú (Otro), porque es proximidad e intimidad. El ente siempre será una mediación del cual se hablará, se interpretará y se organizará a partir de una alteridad. Dicha alteridad es la madre primigenia, luego estará el padre. Por extensión, la alteridad se extiende no sólo hacia la madre y el padre sino también hacia el maestro, el profesor, los hermanos, etcétera, quienes nos introducirán en el mundo de los entes, en nuestro propio mundo (contextual) y en un mundo de sentido.

\section{Alteridad y analéctica}

En la alteridad existe relación irrespectiva, encuentro y diálogo entre libertades. El diálogo es entre 'el Mismo' y 'el Otro’ y es un diálogo histórico que no termina nunca sino que se extiende ad infinitum. Dussel (127) piensa que el ser humano desde la concepción intrauterina es un punto de libertad distinto y exterioridad por sí misma, que exigirá justicia porque tiene derechos. En otras palabras es un ser ético y metafísico, por ende distinto y fundamentalmente 'alterativo' (ibíd.: 128).

La analéctica de la alteridad se concreta en el vínculo estrecho de varón-mujer (erótica), padres-hijos (pedagógica) y hermano-hermana (política). En la pedagógica la relación es padres-hijos mediados por el diálogo que es respeto mutuo, del yo con el Otro: es relación de sujeto a sujeto y no de sujeto a objeto o de objeto a sujeto o de objeto a objeto. En otras palabras, es el vínculo estrecho entre ser y ser. 


\section{El cara a cara (el Otro) como fuente de la peda- sógica de la liberación}

El cara a cara es el rostro frente al rostro del otro, es la persona frente a frente, es lo inmediato, la intimidad primera y el encuentro mismo de El Uno con el Otro (unicidad y otredad).

En el pensamiento de Dussel (ibíd.: 132) encontramos tres diversos grados de encuentro con el Otro, sean estos: varón-mujer, padres-hijo y hermano-hermano. El grado de encuentro entre varón mujer es máximo, el de padres-hijo es medio y el de hermano-hermano es mínimo. Al grado de alteridad después del encuentro varón-mujer le corresponde la erótica, al de padres-hijo le corresponde la pedagógica y al de hermano-hermano le corresponde la política. Lo que interesa por ahora es la relación de encuentro padres-hijo, propia de la pedagógica. Desde la mirada filosófica, la pedagógica es parte de ésta y le interesa la relación cara a cara del padre-hijo, del maestro-discípulo, del filósofo-no filósofo, etcétera. No hay que confundirla con la pedagogía. Así también la pedagógica converge con la erótica y la política.

Veamos el siguiente esquema tomado de Dussel:

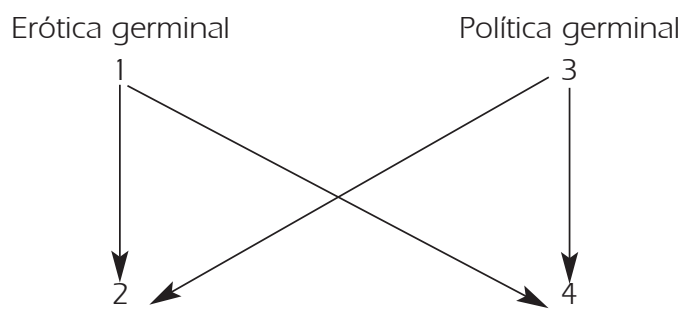

Erótica terminal

Política terminal

Fuente: Dussel 1977: 82 (mecanografiado). 
Expliquemos el esquema antes indicado. Un hijo o una hija nacen en el seno de la familia (1: erótica germinal), luego se educan para ser padre o madre en algún momento de la vida (2: erótica terminal), sin duda se volverán adultos y ciudadanos (4: política terminal); y como niños formarán parte de alguna institución educativa (3: política germinal) que los disciplinará para ser parte responsable de la ciudad (4: política terminal) y terminarán siendo adultos y padre o madre (2: erótica terminal).

El cara a cara de la pedagógica es la metafísica de la exterioridad representada en el hijo o hija que termina de nacer, el maestro y el discípulo o el filósofo y nofilosófo, etcétera. La pedagógica es analéctica por el Otro (hijo, discípulo, no filósofo). A este punto lo que nos interesa es el Otro como distinto, es decir, el discípulo que tiene un nuevo proyecto, real e histórico.

El maestro no deposita conocimientos en el educando al estilo bancario ni enseña conocimientos desde sí mismo sino que ayuda al discípulo a inventarse a sí mismo, aprende con el discípulo y "aprende concomitantemente el pro-yecto del discípulo" (ibíd.: 141). En este sentido la palabra del maestro es profética y subversiva, en el sentido de que todo lo subvierte para bien.

\section{El estar-siendo como categoría ontológica, histórica y metafísica del Otro como otro}

En una de las conferencias sobre desarrollo posible para América Latina, José de Souza ${ }^{8}$ decía que se ha vuelto imperativo categórico descolonizar la dicotomía superior e inferior y ultrapasar "de lo universal, mecánico y neutral a lo contextual, interactivo y ético". Esta hermenéutica pone sobre la mesa que el ser humano es un ser 
situado en el mundo-con otros-junto a otros; en otras palabras, está situado en el aquí y el ahora, por lo que se trata de una espacialidad y temporalidad propias de su condición existencial. El ser humano está siendo junto con otros.

¿Qué significa estar siendo? Para Kusch ${ }^{9}$ el estar es una 'estructura existencial' previa a todo conocimiento predicativo; así también, es un 'principio vital' que se fundamenta en la permanencia del impulso de la 'resistencia' y del 'saber habérsela' subsumida en lo escabroso de la existencia. El estar resiste o sobrevive de cualquier forma entre la coseidad y la misma naturaleza. El estar implica 'vivir con la muerte arrojados al riesgo'. En cambio, siendo es un gerundio que indica el proceso activo del ser, inherente de lo que ya está dado y de la posibilidad de ser, en el horizonte del 'todavía no', o de lo que Dussel (1973: 52) denomina poder-ser futuro que a su vez tiene la modalidad de proyecto.

Kusch ${ }^{10}$ sostiene que el ser define, mientras el estar denota. Desde otro punto de vista, el ser se refiere a la esencia (sub-stancia), al ente, mientras que el estar hace referencia a la ubicación del ente (situado en).

En América, el ser pasa por el reconocimiento legítimo y autolegítimo de lo que sé es, lo que está dado y lo que está siendo como parte fundante de su realidad ontológica; no por el reconocimiento de lo que pueda hacer la modernidad occidental sino por su volcamiento hacia adentro de nosotros mismos, para desentrañarnos en nuestra propia autenticidad. Al respecto la propuesta de Kusch (ibíd.: 116) consiste en pensar que nuestra autenticidad radica en "desenvolver la estructura inversa a dicha autenticidad [se refiere a la occidental] en la forma del estar siendo" como única posibilidad. El ser de América es otra modalidad de esencialización, dado a 
partir de un horizonte identitario auténtico y apegado a su primigenia realidad ontogenética, ontológica y metafísica.

Otro aspecto relevante del planteamiento supra indicado hace relación al ser humano como el estar siendo junto con otros, me refiero fundamentalmente a la nostridad. De alguna manera, hasta aquí, hemos mencionado la yoidad y la otredad como modalidades definitorias del ser yo y ser tú, pero no hemos expresado para nada la categoría epistémica de la nostridad como superación a la categoría de la alteridad.

La nostridad tiene su antecedente previo en la sociabilidad como capacidad inherente de todo ser humano. De hecho, no existe ser humano en sí, ni por sí mismo sin la relación con otros. Requerimos de los otros para ser lo que somos y estaremos siendo. La finitud óntica del ser humano es compensada por la intervención humanitaria de los otros, a través de la ayuda mutua, solidaria y de justicia. La nostridad equilibra dialécticamente la tendencia al yo (egoidad) y la alteridad (otredad). El nos-otros configura en cierto modo un cuerpo social (denomínese familia, clan, estado, entre otros) que equilibra los intereses de los individuos entre sí y con los otros. De acuerdo con Manzanera 11: "La egoidad y la nostridad se oponen al egoísmo individual y al egotismo colectivo (nostrismo)". Desde otra perspectiva diríamos que la nostridad conjuga los ideales éticos de justicia, amistad y misericordia; tres valores interligados por sí mismos y como fuente de la ética y del derecho. Estos principios a su vez son fuente de la filosofía de la nostridad social pública (politicidad), de la 'universidalidad' y 'teologalidad'. La primera relacionada con la polis, es decir, la sociedad cívico-política, la segunda con el principio de universalidad humana (todos somos iguales en dignidad por naturaleza) y la tercera, la 
infinitud humana teniendo como fuente suprema al Verbo - al inicio era el Verbo y el Verbo era Dios.

El nos-otros contiene el cara a cara de la amistad y del amor (agapé) que en la unidad se conjuga en la común-unidad, en el pueblo. La comunidad corresponde a todos como personas, en su singularidad como en su colectividad; la comunidad es de seres libres porque sólo allí se realiza plenamente la individualidad, en la real y suma comunicación comunitaria; Dussel (1986: 19) sostendrá que "La comunidad es el sujeto real y motor de la historia; en ella estamos 'en casa', en seguridad, en común". Sólo en la comunidad somos directamente con otros y junto a otros, no es posible en la naturaleza ni por ella misma.

\section{Praxis permanente del método dialógico como estrategia de liberación}

Aclaremos los términos praxis, método y dialógico. La praxis hace relación a la prágmática, a los actos en su forma terminada o, lo que es lo mismo, a la realidad de los actos. Marx sostenía que el hombre muestra su verdad en la realidad de sus actos: "Es en la práctica donde el hombre debe demostrar la Verdad, es decir, la Realidad y el Poder, la terrenalidad de su pensamiento" (Dusell, 2006: 502). La praxis se refleja tanto en los actos de habla de cada persona, en las prácticas discursivas, como en los mismos actos históricos de colectivos y comunidades humanas que se movilizan multitudinariamente en contra de un adversario $\mathrm{X}$ para lograr fines y procesos democráticos propios de la polis. En relación al método, del latín meth_dus, término que indica visión, camino, procedimiento, estrategia, con el objeto de lograr algo. En el presente estudio se usará en calidad de estrategia. En cam- 
bio, con la dialógica haremos mención al diálogo como praxis del verbo, comunicación y liberación humana.

\section{Esquema dialógico}

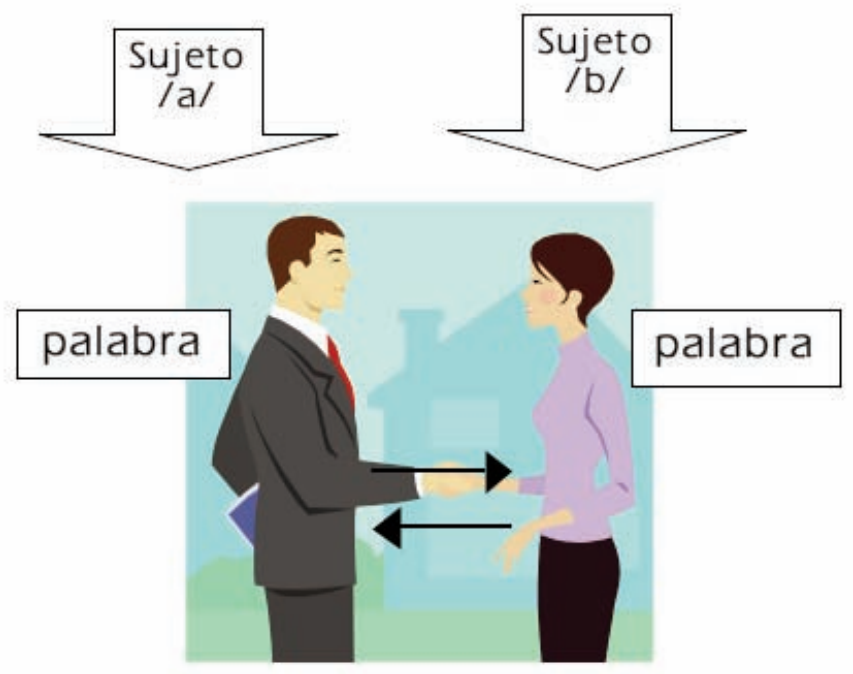

En el cara a cara entre personas, en el encuentro entre corporalidades humanas (relaciones del sujeto /a/ y /b/ del esquema), lo primero que aflora es la palabra mediada por la boca como aparato de fonación humana. La palabra, digamos el verbo ${ }^{12}$ es la mediación relacional que se establece entre sujetos $/ \mathrm{a} / \mathrm{y} / \mathrm{b} /$, de $/ \mathrm{a} / \mathrm{con} / \mathrm{b} / \mathrm{y}$ de $/ \mathrm{b} /$ con $/ \mathrm{a} /$, con el objeto de comprender la verdad que es subjetiva, intersubjetiva y objetiva, tanto de sí mismos como de la realidad del mundo circundante. En ese encuentro intersubjetivo, los sujetos establecen relaciones de diálogo y comunicación. El diálogo implica por lo menos dos interlocutores que verbalizan códigos linguísticos convencionales o arbitrarios y códigos extralingüís- 
ticos, como las señales corporales que son decodificadas para una mutua comprensión de sí mismos o del mundo que los rodea. La comprensión dialógica implica de quién (humanidad) o de qué cosa (naturaleza) se habla; se trata de la substancia del diálogo y el contexto mismo del que se habla.

En esta primera aproximación a la verdad del diálogo podríamos asentir que el diálogo entonces es una acción, una praxis. La praxis del diálogo entre sujetos se da a través de la comunicación, entendida ésta como la relación estrecha entre sujetos que dicen algo sobre sí mismos y del mundo que los circunda. La comunicación es de ida y vuelta (tal como lo mostramos en el esquema supra), codifica y decodifica, denota y connota. La comunicación está mediada por el verbo en relaciones de igualdad de condiciones humanas (razón dialógica). Freire (1977: 99) sostendrá que la 'palabra' misma 'es el diálogo mismo', pero la palabra es mucho más que un medio porque se extenderá a otras dimensiones identificadas como 'acción y reflexión' para la transformación del mundo. El verbo que no es auténtico no puede modificar el mundo, si se le quita la dimensión activa, entonces el verbo se trastorna en verbalismo, por ende alienado y alienante. Un claro ejemplo de verbalismos son los diferentes discursos populistas ejercitados en América Latina por los políticos para llegar al poder de los Estados y la dominación de las multitudes o pueblos ${ }^{13}$. Contrariamente, la pura acción desprovista de la reflexión deviene en activismo; como puede verse, ambos extremos son incompatibles con el verbo.

El diálogo viene a ser una demanda existencial entre sujetos y un acto creador; como tal implica un profundo amor al mundo y a los seres humanos. El amor es fundamento del diálogo y compromiso con los seres huma- 
nos. Si el amor es substancialmente agapé, entonces, sólo entonces es compromiso con el otro, entendido como oprimido (víctima), es decir, promesa por su causa que es razón de su liberación. El compromiso amoroso es dialógico.

El diálogo conlleva una profunda fe por los seres humanos, creencia en ellos, de lo que son y como son, por su dignidad, incluso antes de encontrarse con aquellos; sin la fe en los seres humanos, el diálogo no es más que una falacia que se expresa en una distorsión paternalista:

El hombre dialógico tiene fe en los hombres antes de encontrarse frente a frente con ellos. Ésta, sin embargo, no es una fe ingenua. El hombre dialógico que es crítico sabe que el poder de hacer, de crear, de transformar, es un poder de los hombres y sabe también que ellos pueden, enajenados en una situación concreta, tener ese poder disminuido (Freire, 1977: 104).

Freire en su obra, la Educación como práctica de la libertad asevera que el diálogo "es una relación horizontal de A más B" y, por ende, comunica debido al amor, a la esperanza y a la fe de unos con otros. Así también, el diálogo se expresa en un componente constante de acción liberadora porque es verdadero, auténtico. No es auténtico si existe adulteramiento de la verdad. Jesús de Nazareth decía que la verdad os hará libres; sólo la verdad hará seres humanos libres. No es la libertad liberal — de mercado-. Se trata de la libertad como práctica de la justicia y el derecho, esto es, la libertad como emancipación de las relaciones de maldad inherentes al ser humano y entre seres humanos. Si bien es cierto, la maldad nace en el seno de cada individuo, no obstante, el pecado es social y de estructuras societales, de tal modo se infiere la existencia real del pecado estructural en la sociedad y de las estructuras de pecado social. Dussel (1986c: 29) en su ya citada, Ética comunitaria, sostendrá que en último término, la maldad o pecado "siempre es en relación con otros". 
En el campo de la educación, Freire partirá de la idea de que el pueblo latinoamericano vive y sobrevive en relaciones de opresión producidas por fuerzas sociales poderosas que no permiten su liberación. Las clases opresoras han generado un tipo de educación propio de su dominación, anclada en la larga historia de occidente, denominada por él como 'educación bancaria' (Freire, 1977a: 71 y ss.), que es propia de privilegiados. En cambio, los oprimidos ante las fuerzas antagónicas de la opresión deben tomar conciencia para enfrentar la dominación; uno de los planteamientos freireanos es el de la educación problematizadora que se empeña en la desmitificación por medio del diálogo con el fin de descubrir y comprender la realidad; a través del diálogo se arriba a la comprensión del mundo y de su realidad pero con amor (agapé). Según Freire (Ocampo López, s/a: 10) el diálogo requiere de la investigación científica y pedagógica por medio de la cual se llega a la creatividad y la transformación. El diálogo y la investigación son fundamentales y trascendentales para la educación liberadora de los oprimidos, porque ésta libera a los seres humanos de la dependencia y conciencia a los mismos para que conozcan su realidad y busquen las transformaciones necesarias para su desarrollo relevante. De tal modo, los oprimidos lograrán su liberación cuando hayan tomado conciencia de su situación socio-histórica-cultural. La liberación llegará cuando sea una praxis de liberación o "acción reflexiva de los oprimidos sobre las estructuras opresoras para transformarlas" (ibíd.: 11). En este marco, no cabe duda que la educación sea concebida como práctica de la libertad, es decir, de la verdad que nos hará libres. 


\section{Conclusiones}

La pedagógica de la liberación se opone a una larga tradición pedagógica monárquica, aristocrática y de burguesía imperial que tiene como fondo la pedagógica de la autoridad greco-romana, medieval y moderna, en general asumida para sí por la cristiandad greco-latinagermánica occidental (como ego dominador). La cristiandad occidental mediante la Santa Sede organizó en su matriz religiosa la estructura político-burocrática y educativa muy eficiente que se extendió al inicio de la modernidad temprana en las Américas o hispano lusitano (1492 en adelante) con Ginés de Sepúlveda, Francisco Suárez, y otros posteriores. A la vez, desde Bartolomé de las Casas, Vitoria y otros, quienes se opondrán a la conquista de las tierras que están más allá del Atlántico, se dará principio a una larga trayectoria de oposición crítica y de liberación de las Américas, que continúa hasta ahora. En este sentido la pedagógica de la liberación no es más que la continuidad del pensamiento filosófico del cara a cara, indicado antes, que reflexiona en torno a la relación padre-hijo, maestro-discípulo, político-ciudadano, etcétera.

El reconocimiento ontológico, histórico y metafísico de lo que somos y estamos siendo en las Américas implica otra modalidad de hermeneútica situacional, contextual y existencial del ser latinoamericano. La modalidad radica en la opción política fundamental por la liberación de las relaciones estructurales de pecado e injusticia societal con el Otro, pensado como víctima del sistema vigente. El Otro es injusticiado, la víctima es producto de injusticia y el empobrecido no es más que la revelación de dicha injusticia, por ende, no cabe la opción preferencial por los pobres sino la opción por las víctimas por sí y para sí mismas. 
Por último, hemos hecho referencia al método dialógico como praxis que se inscribe en el método crítico para una reconstrucción histórica de lo que somos y estamos siendo. El método crítico se ubica en el mundo de la vida de las víctimas [inteligidas como negras, indígenas, mestizas, pueblos explotados, entre otros], que es la gran mayoría del pueblo latinoamericano y otredades del mundo; el método como lugar epistemológico nos permite deconstruir las patologías, paranoias y esquizofrenias del Estado moderno y, a la vez, plantear como única salida la dialógica [incluye el polílogo] como mecanismo de liberación humana.

A manera de provocación interlocutiva hemos querido plantear los desafíos de la pedagógica de la liberación sabiendo que es expresamente el inicio de la comprehensión ontológica ya emprendida por muchos autores en América Latina e impeler el camino trazado por el pensamiento divergente de la región.

Finalmente, en el límite de lo que hemos trazado como desafíos indicados a lo largo de la presente exposición, nos queda por proseguir en la resignificación de los 'saberes' y 'disciplinas científicas' a partir de nuestro lugar hermeneútico. Así también en el horizonte del deber-ser (proyecto) debemos deconstruir y revisar la praxis de la disciplina pedagógica, para pasar de una pedagogía de la dominación a una pedagogía de la liberación. Evidentemente, como todo proyecto de liberación debemos profundizar la comunicación como parte del método dialógico práxico.

\section{Notas}

1 En América Latina, el padre machista está representado en el Estado, primero imperial y luego colonial, y se opone a la madre como cultura, violentada por el Estado. 
2 Jorge Dávalos S.J., "Lo político-social desde la filosofía de Zubiri. Un planteamiento epistemológico", en J.C. Scannone S.I., V. Santuc S.I. Compiladores, Lo político en América Latina. Desafíos Actuales. Contribución filosófica a un nuevo modo de hacer política, Equipo Jesuita Latinoamericano de reflexión filosófica, Argentina: Editorial Bonum, 1999, 23.

3 El Catoblepas es un antiguo animal mitológico griego, el cual mira hacia abajo. Algunos clásicos griegos, como Elieno, Ateneo y Arquelao y otros de origen latino, como Plinio, Solino y Pomponio Mela le otorgaban a dicho animal la capacidad de matar a quien mire a sus ojos: el animal esconde sus ojos hacia la tierra porque no tiene deseo de utilizar su poder mortal, pero si alguien lo mira a los ojos termina fulminado.

4 Enrique Dussel, 1492 El encubrimiento del otro, Hacia el origen del "mito de la modernidad". Colección Academia -Facultad de Humanidades y Ciencias de la Educación Universidad Mayo de San Andrés, Bolivia: Plural Editores, Centro de Información para el Desarrollo (CID), 1994, 3, (mecanografiado).

5 Aníbal Quijano, Colonialidad del poder y clasificación social. Introducción, Journal of "World-System Research, VI, 2, Summer/ Fall 2000, 342-386, Special Issue: Festchrift for Immanuel Wallerstein - Part I, Lima-Perú, 2000 b, 342.

6 La analéctica es el método del pensar latinoamericano acuñado por Dussel para llevar adelante la tarea filosófica. Se trata del método metafísico [más allá] distinto al dialéctico; analéctico viene de más allá para interpretar el mundo. El punto de partida del método es el Otro como oprimido, denominado en este estudio como víctima y víctima del sistema capitalista actual.

7 Según Hardt y Negri, en su discurso de el Otro distinto, "Marx sólo puede concebir la historia que se desarrolla fuera de Europa como un movimiento que sigue estrictamente el camino ya recorrido por la propia Europa. 'Inglaterra tiene que cumplir una doble misión en la India' -escribía Marx-, una destructiva y la otra regeneradora: la aniquilación de la antigua sociedad asiática y el establecimiento de las bases materiales de la sociedad occidental en Asia"; Michael Hardt y Antonio Negri, Op. Cit., 2002, 114; también véase: Karl Marx, "The Future Results of British Rule in India”, 320.

8 José de Souza Silva, “¿Qué desarrollo es posible?”, en: Universidad, Desarrollo y Cooperación. Memorias I Congreso Internacional, Universidad Politécnica Salesiana Ecuador, Cuenca: 25 a 27 de abril, 2008, 27. 
9 José Aliante Escárate, "De textos y pretextos o, de la exigencia académica de la cita para justificar un presente mediante un ausente, y de la posibilidad filosófica de un texto auténtico sin citas", en: Hermenéutica Intercultural, Revista de Filosofía $N^{\circ} 16$, Universidad Católica Silva Enríquez, 2007, 7.

10 Rodolfo Kusch, "El "estar-siendo como estructura existencial y como decisión cultural americana", en Temas de Antropología Latinoamericana, Colección Antología 2, Bogotá: Editorial El Búho, 1989, 109.

11 Miguel Manzanera, S.J., “4. Derecho, Política y Ética. Fundamentación en la filosofía de la nostridad", en J.C. Scannone S.I., V. Santuc S.I. Compiladores, Lo politico en América Latina. Desafios Actuales. Contribución filosófica a un nuevo modo de hacer política. Equipo Jesuita Latinoamericano de reflexión filosófica, Argentina: Editorial Bonum, 1999, 225.

12 El evangelista Juan hace referencia a la Palabra como "Verbo". Afirma que en el principio existía el Verbo y el Verbo estaba ante Dios, y el Verbo era Dios." Y todo se hizo por el Verbo.

13 Enrique Dussel, Politica de la liberación. Historia mundial y crítica, Colección Estructuras y Procesos, Serie Filosofía, Madrid: Editorial Trotta S.A., 2007, 435 y ss.

\section{Bibliografía}

ALIANTE ESCÁRATE, José Gustavo

2007 "De textos y pretextos o, de la exigencia académica de la cita para justificar un presente mediante un ausente, y de la posibilidad filosófica de un texto auténtico sin citas", en: Hermenéutica Intercultural, Revista de Filosofía $\mathrm{N}^{\circ} 16$, Universidad Católica, Silva Enriquez (pdf).

DÁVALOS, Jorge, S.J.

1999 "Lo político-social desde la filosofía de Zubiri. Un planteamiento epistemológico", en J.C. Scannone S.I., V. Santuc S.I. Compiladores, Lo politico en América Latina. Desafíos Actuales. Contribución filosófica a un nuevo modo de hacer política. Equipo Jesuita Latinoamericano de reflexión filosófica, Argentina: Editorial Bonum.

DUSSEL, Enrique

1994a 1492 El encubrimiento del otro. Hacia el origen del "mito de la modernidad". Colección Academia-Facultad de Huma- 
nidades y Ciencias de la Educación Universidad Mayo de San Andrés, Bolivia: Plural Editores, Centro de Información para el Desarrollo (CID), 1994 a.

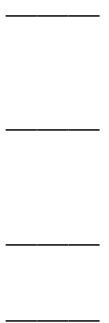

Para una Ética de la liberación latinoamericana. Primera edición, Tomo I, Argentina: Siglo Veintiuno Argentina Editores, S.A., 1973 b.

Filosofía Ética Latinoamericana. De la Erótica a la Pedagógica 6/III. Primera edición, México: Editorial Edicol, S.A. (mecanografiado), $1977 \mathrm{c}$.

Ética Comunitaria, Cuenca, Ecuador: Ediciones Cristianas del Azuay, 1986 d.

Ética de la Liberación en la Edad de la Globalización y de la Exclusión, Colección Estructuras y Procesos, Serie Filosofía, Quinta edición, Madrid: Editorial Trotta, S.A., 2006 e.

Politica de la liberación. Historia mundial y crítica, Colección Estructuras y Procesos, Serie Filosofía, Madrid: Editorial Trotta S.A., $2007 \mathrm{f}$.

FREIRE, Paulo

1977a Pedagogía del Oprimido, 16a edición, Colombia: Siglo Veintiuno Editores, S.A.

_L La educación como práctica de la libertad, Argentina: Siglo Veintiuno Argentina Editores, S.A., 1973 b.

HARDT, Michael y Antonio Negri

2002 Imperio, Primera edición, Buenos Aires: Editorial Paidós SAICF.

KUSCH, Rodolfo

1989 "El "estar-siendo como estructura existencial y como decisión cultural americana", en Temas de Antropología Latinoamericana, Colección Antología 2, Bogotá: Editorial El Búho,.

LANDER, Edgardo

s/f Ciencias Sociales: saberes coloniales y eurocéntricos, Universidad Central de Venezuela, Caracas, pdf.

LEVINAS, Emmanuel

1977 Totalidad e Infinito, Ensayo sobre la exterioridad, Salamanca: Ediciones Sígueme.

MANZANERA, Miguel, S.J.

1999 “4. Derecho, Política y Etica. Fundamentación en la filosofía de la nostridad", en J.C. Scannone S.I., V. Santuc S.I. Compiladores, Lo politico en América Latina. Desafíos 
Actuales. Contribución filosófica a un nuevo modo de hacer política, Equipo Jesuita Latinoamericano de reflexión filosófica, Argentina: Editorial Bonum.

MARX, Karl

1973 "The Future Results of British Rule in India", en Surveys Form Exile, vol. 2 de Politica Wittings, Londres, Perguin.

MOREANO, Alejandro

2002 El Apocalipsis perpetuo, Primera edición, Quito: Editorial Planeta del Ecuador S.A.

OCAMPO LÓPEZ, Javier

s/f Paulo Freire y la pedagogía del oprimido, Universidad Peda gógica y Tecnológica de Colombia, RudeColombia.

QUIJANO, Aníbal

2000a Colonialidad del poder, eurocentrismo y América Latina, Primera impresión, Argentina: Taller de Gráficas y Servicios.

Colonialidad del poder y clasificación social. Introducción. Journal of "World-System Research, VI, 2, Summer/Fall 2000, 342-386, Special Issue: Festchrift for Immanuel Wallerstein - Part I, Lima-Perú, 2000 b.

SILVA, José de Souza

2007 “Qué desarrollo es posible?”, en: Universidad, Desarrollo y Cooperación, Memorias I Congreso Internacional, Universidad Politécnica Salesiana Ecuador, Cuenca: 25 a 27 de abril.

NIMMO, Jan

2004 (documental), Coproductora y Editora: Cassandra McGrogan, Sonido: John Cobban y Craig Aitchison, música: los Reyes del Vallenato, apoyado por: Banana link, CTDU (Unidad de Entrenamiento y Desarrollo Comunitario, Escocia), producción de Cacomistle. 